Case Report

Joumal of Epilepsy Research pISSN 2233-6249 / eISSN 2233-6257

Received December 10, 2018

Revised December 12, 2018

Accepted December 21, 2018

Corresponding author:

Won Gu Lee, MD

Department of Neurology, Kosin University

College of Medicine, 262 Gamcheon-ro,

Seo-gu, Busan 49267, Korea

Tel. +82-51-990-6461

Fax. +82-51-990-3077

E-mail; neogio219@hanmail.net

\title{
Carbon Monoxide Poisoning Presenting as Non-Convulsive Status Epilepticus Treated with Hyperbaric Oxygen Therapy
}

\author{
Won Gu Lee, MD \\ Department of Neurology, Kosin University College of Medicine, Busan, Korea
}

\begin{abstract}
Carbon monoxide ( $\mathrm{CO}$ ) poisoning is one of the most serious medical emergencies causing life-threatening conditions, including cardiovascular and neurological sequelae. Acute $\mathrm{CO}$ poisoning can lead to myocardial ischemia, ventricular arrhythmia, syncope, seizures, and coma. Seizures and other neurological complications in the early stages of presentation are related to severe intoxication in $\mathrm{CO}$ poisoning. In such situations, aggressive hyperbaric oxygen therapy is recommended. In $\mathrm{CO}$ poisoning, non-convulsive status epilepticus has rarely been observed following hyperbaric oxygen therapy $\left(\mathrm{HBO}_{2}\right)$. We report a case of $\mathrm{CO}$ poisoning presenting as non-convulsive status epilepticus treated with $\mathrm{HBO}_{2}$. Mechanisms and implications for non-convulsive status epilepticus provocation during $\mathrm{HBO}_{2}$ treatment are discussed. (2018;8:100-104)
\end{abstract}

Key words: Carbon monoxide poisoning, Status epilepticus, Hyperbaric oxygenation

\section{Introduction}

Carbon monoxide (CO) poisoning is a medical emergency that leads to cardiovascular and neurological complications. ${ }^{1}$ The clinical manifestations of $\mathrm{CO}$ poisoning are nonspecific, and various neurologic abnormalities, such as confusion, seizures, and coma, may occur at higher levels of carboxyhemoglobin $(\mathrm{COHb}) .{ }^{1}$ Various reports show self-limiting seizures, but status epilepticus has rarely been reported in patients with $\mathrm{CO}$ poisoning. ${ }^{1,2}$ Furthermore, hyperbaric oxygen therapy $\left(\mathrm{HBO}_{2}\right)$ may result in late-onset neurological sequelae. ${ }^{3}$ The exact pathogenesis underlying $\mathrm{HBO}_{2}$ and status epilepticus associated with $\mathrm{CO}$ poisoning is not yet clear. Herein, we present a patient who developed non-convulsive status epilepticus after acute $\mathrm{CO}$ poisoning treated with $\mathrm{HBO}_{2}$ therapy.

\section{Case}

A 71-year-old woman attempted suicide by burning charcoal at home. She was found unconscious after 3 hours of exposure to $\mathrm{CO}$ from the burning charcoal. Apart from burning charcoal, she also took an unknown amount of hypnotic drugs. She had been treated with risperidone, amitriptyline, and escitalopram for paranoid schizophrenia and bipolar disorder during 10 years. On arrival at our emergency room, she was unconscious with a Glasgow coma scale (GCS) score of 7/15. The pupils were bilaterally equal, $3 \mathrm{~mm}$ in size and reactive to light. Examination of the vital signs found an oral body temperature of $37^{\circ} \mathrm{C}$, a regular pulse of 93 beats $/ \mathrm{min}$, blood pressure of $67 / 45 \mathrm{mmHg}$, and pulse oximetry of $93 \%$ in room air. Her arterial blood gas results in room air were as follows: pH 7.48, $\mathrm{PaCO}_{2} 32$ $\mathrm{mmHg}, \mathrm{PaO}_{2} 50 \mathrm{mmHg}$, base excess $-2.1 \mathrm{mmol} / \mathrm{L}, \mathrm{SaO}_{2} 95.2 \%$, and $\mathrm{COHb} 19.3 \%$. Laboratory tests found a serum prolactin level of $69.19 \mathrm{ng} / \mathrm{mL}$, high sensitivity-C reactive protein (hs-CRP) level of $1.719 \mathrm{mg} / \mathrm{dL}$, and erythrocyte sedimentation rate (ESR) of $15 \mathrm{~mm} / \mathrm{h}$. No abnormalities were detected in the cerebrospinal fluid except for mildly elevated protein contents of $51 \mathrm{mg} / \mathrm{dL}$. Urine toxicology screening tests gave negative results. Other results of blood chemistry was normal. Electrocardiography revealed sinus tachycardia without a change in the ST segment. Brain magnetic resonance imaging showed bilaterally symmetric focal abnormalities involving the globus pallidi (Fig. 1). CO poisoning was suspected because of the increased level of $\mathrm{COHb}(19.3 \%)$ and $100 \%$ oxygen administration was initiated. She underwent three $\mathrm{HBO}_{2}$ sessions over the course of 3 days. Following $\mathrm{HBO}_{2}$ therapy, the patient recovered spontaneous respiration and the tube was removed. On neurological examination, she was found to be alert and able to communicate normally (GCS 13). On day 28 , she was unconscious with a GCS score of 3/15 and her $\mathrm{COHb}$ level was $0.9 \%$. Magnetic resonance imaging revealed a diffuse, confluent hyperintensity on T2-weighted 
sequences in bilateral cerebral white matter, suggesting demyelination of the cerebral white matter (Fig. 2). An electroencephalogram (EEG) was performed and showed continuous and diffuse high amplitude paroxysmal sharp waves at 2-3 Hz (Fig. 3A). She was diagnosed with non-convulsive status epilepticus and intravenous infusion of 1,000 mg of levetiracetam and 1,500 $\mathrm{mg}$ of valproic acid was therefore administered. Continuous EEG monitoring showed an absence of epileptiform activity (Fig. 3B). On day 40 after CO poisoning, she was semi-comatose with rare responses to painful stimuli and transferred to a nursing hospital without any recovery (GCS 3).

\section{Discussion}

We experienced a patient with $\mathrm{CO}$ poisoning with non-convulsive status epilepticus treated with $\mathrm{HBO}_{2}$. $\mathrm{CO}$ is an odorless, colorless, and nonirritant gas produced by the incomplete combustion of carbon-based fuels. The clinical features of CO poisoning are nonspecific, and physicians may consider a broad range of diagnostic possibilities.

In the present case, several differential diagnoses can be considered as potential causes of mental deterioration with non-convulsive status epilepticus. Firstly, past medical history of the patient revealed that she had been under treatment with risperidone, amitriptyline, and escitalopram for paranoid schizophrenia and bipolar disorder, which can give rise to drug intoxication resulting in seizures. Acute drug intoxication is a condition that follows the administration of a psychoactive substance and results in disturbances in the level of consciousness, cognition, perception, judgement, or seizure, or other psychophysiological functions and responses. Antidepressant drugs, such as amitriptyline and escitalopram, and atypical antipsychotic
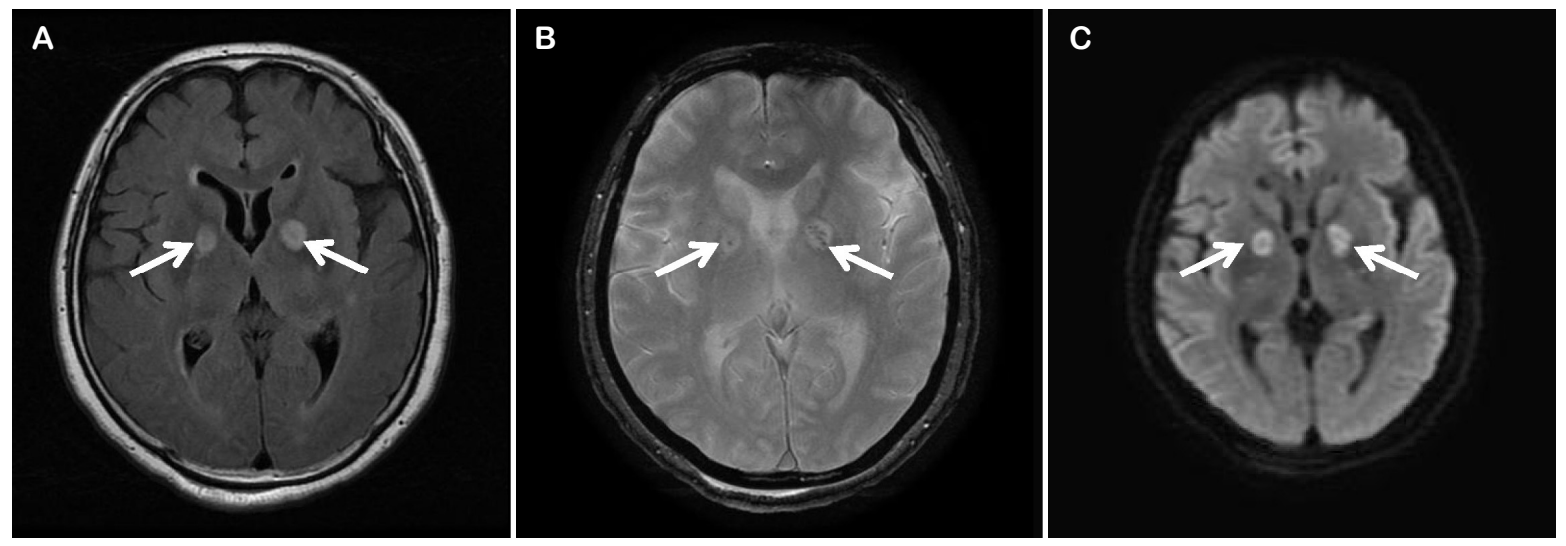

Figure 1. Brain MRI of the patient. Carbon monoxide poisoning in a 61-year-old woman who was in a coma after a suicide attempt. Magnetic resonance images depict bilaterally symmetric focal abnormalities in the globus pallidus interna lesion (arrows) with hyperintensity on axial fluid-attenuated inversion recovery $(A)$, hypointensity on $2^{*}$-weighted gradient-echo $(B)$, and hyperintensity on diffusion weighted imaging (C). MRI, magnetic resonance imaging.
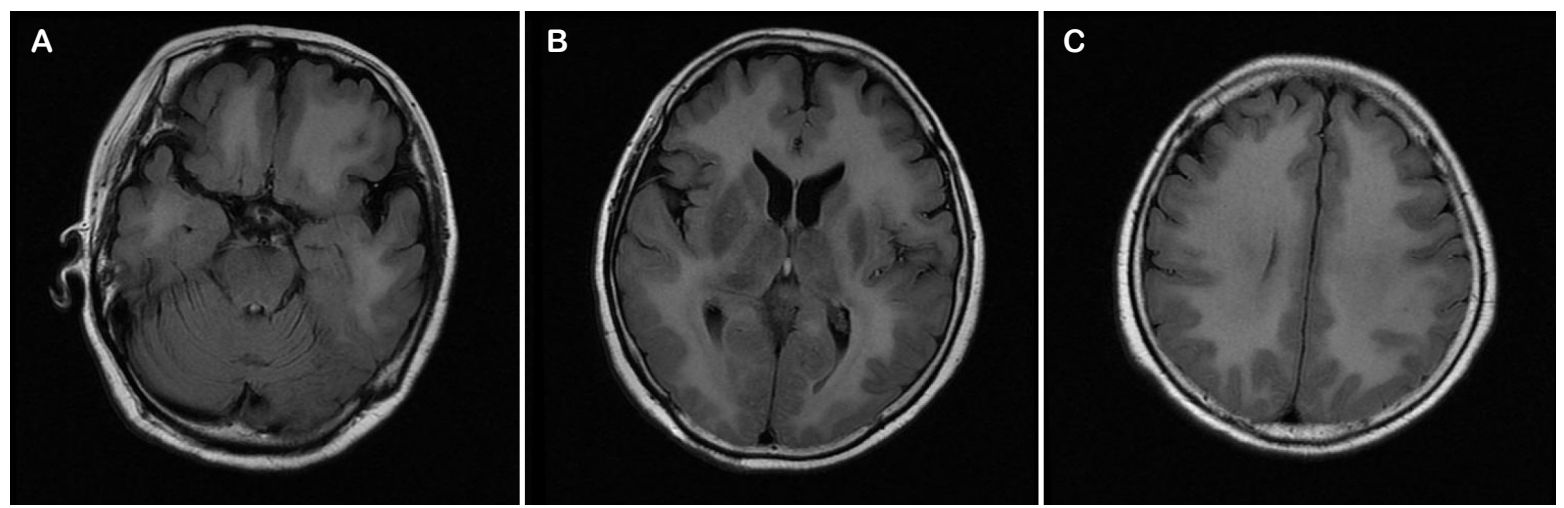

Figure 2. Brain MRI. T2 fluid-attenuated inversion recovery axial images from three different levels: (A) hippocampal cortex, (B) globus pallidus, and (C) semioval center at 40 days from $\mathrm{CO}$ poisoning. MRI, magnetic resonance imaging; $\mathrm{CO}$, carbon monoxide. 


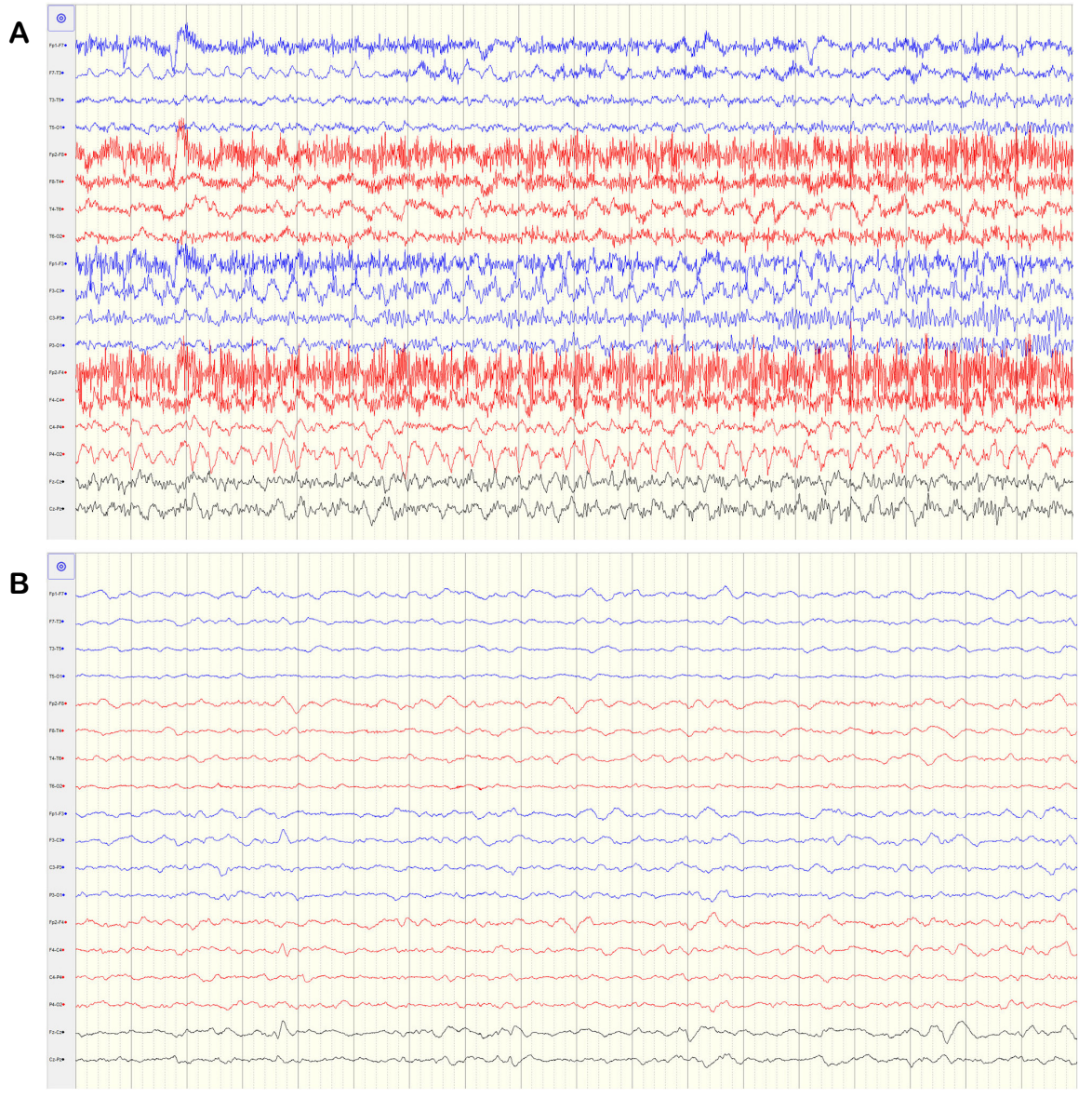

Figure 3. Patient EEG. (A) Routine EEG displayed in a longitudinal bipolar montage reveals continuous 2- to 3-Hz generalized sharp wave discharges. (B) After administration of intravenous levetiracetam and valproic acid, continuous EEG monitoring shows no epileptiform activity. EEG, electroencephalography.

medication are known to have a proconvulsive effect. ${ }^{4}$ However, in this case, drug intoxication induced seizure seemed highly unlikely because she took usual drug dose and her urine toxicology tests were normal. Second, metabolic causes of acute altered mental status must also be ruled out and are common among the elderly with underlying medical conditions. Metabolic causes of altered mental status include hypo/hyperglycemia, electrolyte abnormalities, uremia, hepatic encephalopathy, hypertensive encephalopathy, metabolic encephalopathy, and hypo/hyperthyroidism. ${ }^{5}$ Acute metabolic encephalopathy is a condition of global cerebral dysfunction in the absence of primary structural brain disease.

However, in our case, her blood chemistry was normal except for elevated prolactin, hs-CRP, and ESR level and brain magnetic resonance imaging showed bilaterally symmetric focal lesions involving the globus pallidi. Finally, while central nervous system (CNS) infection can also induce status epilepticus, the results of cerebrospinal fluid analyses were incompatible with the presence of infection. In this particular case, the patient was discovered after 3 hours of exposure to the charcoal fumes. These circumstances may lead to $\mathrm{CO}$ intoxication and consecutive non-convulsive status epilepticus.

In the early stages of $\mathrm{CO}$ poisoning, most patients present with various neurologic complications, including apathy, amnesia, disorientation, extra-pyramidal symptoms, psychosis, seizure, and coma. ${ }^{6}$ In adults, mild symptoms, such as headache, dizziness, palpitation, and nausea, are typical in patients with $\mathrm{COHb}$ levels of 10-30\%. ${ }^{6}$ Seizures are generally thought to occur when the $\mathrm{COHb}$ level reaches more than $40 \%$, but the level does not necessarily correlate with the severity of symptoms. In our experience, the $\mathrm{COHb}$ level was $0.9 \%$ when the patient was diagnosed with non-convulsive status epilepticus. There may be possible hypotheses regarding whether her low $\mathrm{COHb}$ level was related to non-convulsive status epilepticus in the late stages of $\mathrm{CO}$ poisoning. The pathophysiology of this delayed and repeated seizures depends on various mechanisms. $\mathrm{CO}$ has an affinity for hemoglobin 200-250 times greater than that of oxygen, forming $\mathrm{COHb}$ and re- 
ducing the total capacity of the blood to carry oxygen. This results in cerebral hypoxia far out of proportion from what would be expected from the loss of oxygen-carrying capacity. CO causes mitochondrial dysfunction resulting into oxidative stress related damage with elevated levels of excitatory amino acids ( $\mathrm{N}$-methyl-d-aspartate) and brain nitrites. ${ }^{8}$ With reperfusion of the brain, leukocyte adhesion and the release of destructive enzymes amplify the initial oxidative injury. ${ }^{8}$ This delayed seizures may occur even when $\mathrm{COHb}$ level were low. Furthermore, cellular theories such as immunopathological damages and disturbance of dopaminergic and serotonergic functions support the underlying pathophysiology of this delayed seizures. This theory postulates that the delayed but reversible effects were related to the activation of polymorphonuclear leukocytes by the $\mathrm{CO}$, leading to reversible demyelination of the CNS. ${ }^{9}$ In the meanwhile, elderly patients may be at high risk of $\mathrm{CO}$ poisoning because of a slower elimination rate of $\mathrm{CO}$ than pediatric patients. The elderly has an increased neurologic susceptibility to CO poisoning and may experience CNS symptoms at a much lower dose. ${ }^{10}$ In this case, the patient has higher risk for $\mathrm{CO}$ poisoning due to her old age.

We treated a patient with non-convulsive status epilepticus without self-limiting isolated seizures after exposure to repeated $\mathrm{HBO}_{2}$. There are many case reports and retrospective studies demonstrating seizures induced by $\mathrm{HBO}_{2}$ therapy. ${ }^{11} \mathrm{HBO}_{2}$ is the most effective treatment for patients with acute $\mathrm{CO}$ poisoning. The underlying mechanism includes increasing dissolved-oxygen content in the blood and accelerated elimination of $\mathrm{CO}$, with prevention of lipid peroxidation and preservation of adenosine triphosphate (ATP) levels in tissue in serious $\mathrm{CO}$ poisoning. ${ }^{12}$

CNS oxygen toxicity is a rare but recognized side effect of $\mathrm{HBO}_{2} \cdot{ }^{13}$ Our case presented non-convulsive status epilepticus after treated with $\mathrm{HBO}_{2}$. The pathogenesis of seizures associated with $\mathrm{HBO}_{2}$ is not fully understood but may be associated with the decrease in the seizure threshold through various mechanisms. Firstly, in CO poisoning treated with $\mathrm{HBO}_{2}$, oxidative stress develops during the ischemic and reperfusion phases and increases the production of nitric oxide (NO) by NO synthase. Increased NO levels inhibit glutamic acid decarboxylase and results in a decrease in gamma-aminobutyric acid levels. ${ }^{14} \mathrm{NO}$ can also have toxic effects by inhibiting aconitase, complex I and II in the electron transport chain, and mitochondrial respiration, resulting in ATP depletion and disruption of the active transport system of the cell. ${ }^{15} \mathrm{NO}$ might cause toxicity by increasing intracellular free calcium by activating the ryanodine receptor. These changes can induce the activation of a series of enzymes and dis- ruption of the cell membrane potential, which might result in seizures. ${ }^{15}$ In mice exposed to $\mathrm{HBO}_{2}$, these changes have been observed in the brain stem, corpus callosum, and cerebral cortex. ${ }^{16}$ Second, brain-derived neurotrophic factor (BDNF), as a survival factor for certain neuronal population, provoked by $\mathrm{HBO}_{2}$ therapy might modify both excitatory and inhibitory synaptic transmission in the brain. ${ }^{17}$ The increased BDNF signaling plays a role in the development of seizure and epileptogenesis. Finally, $\mathrm{HBO}_{2}$-induced changes in cerebral blood flow (CBF) may play a important role in repeated seizure generation. ${ }^{18}$ Increased CBF during seizure might represent epileptogenic zone. In normal conditions, $\mathrm{CBF}$ is regulated by the level of carbon dioxide. However, with prolonged $\mathrm{HBO}_{2}$, cerebral vasodilation might occur and produce free radicals and nitric oxide, predisposing to more convulsions. ${ }^{18}$

Radiologic findings in $\mathrm{CO}$ poisoning are variable. During the acute phase of $\mathrm{CO}$ poisoning, the globus pallidus may be one of the most frequently injured areas. ${ }^{19}$ In delayed encephalopathy, the most common finding is white matter hyperintensity that might be caused by demyelination after $\mathrm{CO}$ poisoning. Sometimes, lesions may be found in the hippocampus or cortex that are correlated with a poor prognosis in the delayed phase of $\mathrm{CO}$ poisoning. ${ }^{19}$ The MR image from our case showed the same involvement and abnormal signal intensity of bilateral basal ganglia in the acute phase and diffuse white matter in the delayed phase. During the early phase of CO poisoning, to better correlate the symptoms with the clinical course, imaging techniques, such as diffusion tensor imaging or diffusion-weighted $\mathrm{MRI}$, may be helpful in detecting white matter lesions. ${ }^{20}$

In conclusion, non-convulsive status epilepticus is rare both after $\mathrm{CO}$ poisoning and $\mathrm{HBO}_{2}$ therapy. Our case demonstrates that clinicians should need to be aware of delayed and fatal complications, such as non-convulsive status epilepticus and perform immediate EEG and MRI when mental status fails to improve after $\mathrm{HBO}_{2}$ therapy in CO poisoning.

\section{References}

1. Herman LY. Carbon monoxide poisoning presenting as an isolated seizure. J Emerg Med 1998;16:429-32.

2. Durnin C. Carbon monoxide poisoning presenting with focal epileptiform seizures. Lancet 1987;1:1319.

3. Chavko M, Xing G, Keyser DO. Increased sensitivity to seizures in repeated exposures to hyperbaric oxygen: role of NOS activation. Brain Res 2001;900:227-33.

4. Alldrege BK. Seizure risk associated with psychotropic drugs: clinical and 
104 Journal of Epilepsy Research Vol. 8, No. 2, 2018

pharmacokinetic considerations. Neurology 1999;53(5 Suppl 2):S68-75.

5. Supanc V, Vargek-Solter V, Demarin V. Metabolic encephalopathies. Acta Clin Croat 2003;42:351-7.

6. Olson KR. Carbon monoxide poisoning: Mechanisms, presentation, and controversies in management. J Emerg Med 1984;1:233-43.

7. Stack S. Media coverage as a risk factor in suicide. I Epidemiol Community Health 2003:57:238-40.

8. Dolan MC. Carbon monoxide poisoning. CMA 1985;133:392-9.

9. Hurley RA, Hopkins RO, Bigler ED, Taber KH. Applications of functional imaging to carbon monoxide poisoning. J Neuropsychiatry Clin Neurosci 2001;13:157-60.

10. Crocker PJ, Walker JS. Pediatric carbon monoxide toxicity. J Emerg Med 1985:3:443-8.

11. Doherty MJ, Hampson NB. Partial seizure provoked by hyperbaric oxygen therapy: possible mechanisms and implications. Epilepsia 2005;46:974-6.

12. Tibbles PM, Edelsberg JS. Hyperbaric-oxygen therapy. N Eng/ J Med 1996;334:1642-8.

13. Hampson NB, Simonson SG, Kramer CC, Piantadosi CA. Central nervous system oxygen toxicity during hyperbaric treatment of patients with carbon monoxide poisoning. Undersea Hyperb Med 1996;23:215-9.

14. Seckin M, Gurgor N, Beckmann YY, Ulukok MD, Suzen A, Basoglu M. Focal status epilepticus induced by hyperbaric oxygen therapy. Neurologist
2011;17:31-3.

15. Stadler J, Billiar TR, Curran RD, Stuehr DJ, Ochoa JB, Simmons RL. Effect of exogenous and endogenous nitric oxide on mitochondrial respiration of rat hepatocytes. Am J Physiol 1991;260(5 Pt 1):C910-6.

16. Mialon P, Joanny P, Gibey $R$, et al. Amino acids and ammonia in the cerebral cortex, the corpus striatum and the brain stem of the mouse prior to the onset and after a seizure induced by hyperbaric oxygen. Brain Res 1995;676:352-7.

17. Chavko M, Nadi NS, Keyser DO. Activation of BDNF mRNA and protein after seizures in hyperbaric oxygen: implications for sensitization to seizures in re-exposures. Neurochem Res 2002;27:1649-53.

18. Visser GH, Van Hulst RA, Wieneke GH, Van Huffelen AC. Transcranial Doppler sonographic measurements of middle cerebral artery flow velocity during hyperbaric oxygen exposures. Undersea Hyperb Med 1996; 23:157-65.

19. Beppu T. The role of MR imaging in assessment of brain damage from carbon monoxide poisoning: a review of the literature. AJNR Am J Neuroradiol 2014;35:625-31.

20. Kwon OY, Chung SP, Ha YR, Yoo IS, Kim SW. Delayed postanoxic encephalopathy after carbon monoxide poisoning. Emerg Med J 2004;21: 250-1. 